\title{
Reconsidering the Role of Procedures for Decision Acceptance
}

\author{
PETER ESAIASSON, MIKAEL PERSSON, MIKAEL GILLJAM \\ AND TORUN LINDHOLM*
}

\begin{abstract}
Procedural fairness theory posits that the way in which authoritative decisions are made strongly impacts people's willingness to accept them. This article challenges this claim by contending that democratic governments can achieve little in terms of acceptance of policy decisions by the procedural means at their disposal. Instead, outcome favorability is the dominant determinant of decision acceptance. The article explicates that while central parts of procedural fairness theory are true, outcome favorability is still overwhelmingly the strongest determinant of individuals' willingness to accept authoritative decisions. It improves on previous research by locating all key variables into one causal model and testing this model using appropriate data. Findings from a large number of experiments (both vignette and field) reproduce the expected relationships from previous research and support the additional predictions.
\end{abstract}

Keywords: procedural fairness; decision acceptance; decision-making procedures

Procedural fairness research has demonstrated that people care strongly about the way authoritative decisions are made. Acknowledging this preference, political scientists have long used procedural fairness theory to inform their analysis of citizens' relationships with democratic authorities. ${ }^{1}$ An important finding in procedural fairness research is that procedures are closely connected with decision acceptance. Drawing out real-world implications of this finding, leading scholars in the field maintain that democratic governments can generate citizen acceptance of difficult decisions if they follow fair procedures when making them. For example, Tyler recommends that authorities should focus on acting 'in ways that encourage judgments that they are using just procedures when exercising their authority'. ${ }^{2}$ And MacCoun $^{3}$ warns that people's preference for fair procedures is so strong that it leaves them 'susceptible to manipulation and exploitation'. ${ }^{4}$

\footnotetext{
* Department of Political Science, University of Gothenburg, Sweden (email: peter.esaiasson @pol.gu.se); Department of Political Science, University of Gothenburg (email: mikael.persson@pol.gu.se); Department of Political Science, University of Gothenburg (email: mikael.gilljam@pol.gu.se); Department of Psychology, Stockholm University, Sweden (email: torun.lindholm@psychology.su.se). Data replication sets are available at http://dataverse.harvard.edu/dataverse/BJPolS and online appendices are available at http://dx.doi.org/ doi:10.1017/S0007123416000508.

${ }^{1}$ E.g., Gangl 2003; Gibson 1989; Grimes 2006; Hibbing and Alford 2004; Tyler 1990; Ulbig 2008.

2 Tyler 2011, 14.

${ }^{3}$ MacCoun 2005.

${ }^{4}$ While usually less drastically expressed, this claim represents conventional wisdom: '(P)rocedural fairness has been shown to have substantial effects on virtually all important organizational outcomes' (van Houwelingen, van Dijke, and De Cremer 2014); 'A major reason why procedural justice is of interest for political theorists is its ability to lessen the impact of unpleasant decisions' (Klosko 2000, 210); 'Findings such as these suggest that experiencing fair procedures builds social values, and these values lead people to feel a long-lasting, personal obligation to accept decisions and support rules' (Hechter 2013, 20).
} 
In this article, we take a new look at the procedure-acceptance connection in the context of policy making. Contrary to conventional wisdom, we contend that democratic governments can achieve little in terms of acceptance of their policy decisions by optimizing the procedural means at their disposal. We do not dispute the key insight from procedural fairness research that people value what they perceive to be fair decision-making procedures. However, we explicate why outcome favorability is nevertheless a much stronger determinant of individuals' willingness to accept policy decisions than the objective procedural arrangements that are available to government authorities.

Our reassessment of the procedure-acceptance connection targets three variables: objective procedural arrangements (the procedural means at democratic governments' disposal), subjective procedural assessments (individuals' evaluations of the fairness of the objective decision-making arrangements, which is the prime causal factor within the procedural fairness literature) and outcome favorability (the degree to which a decision coincides with an individual's preference). As we will explore throughout this article, locating key variables in a properly specified model generates different results than would be expected when looking at the individual parts.

In the following, we first revisit procedural fairness theory to identify the conditions under which objective procedural arrangements for policy decisions generate decision acceptance and to highlight previous research that provides pieces of the puzzle we wish to complete. We discuss the theory in its abstract form as well as how it applies to policy decisions specifically.

Having discussed issues of design, data and measurements, we present findings from twentyeight vignette and field experiments in which objective procedural arrangements are manipulated in a number of ways. The manipulations involve generic arrangements for policy decisions (direct majoritarian voting, representative decision-making and expert decision-making) as well as fair and unfair implementations of generic arrangements for decision-making (for example, whether or not an expert decision-making procedure allows affected individuals to voice concerns pre-decision). Using structural equation modeling to analyze these data, we reproduce all the typical findings from procedural fairness research and find support for the additional predictions that distinguish our study from much previous research in the field. We conclude by discussing the implications of our findings for theory and for authoritative decision-making in the real world.

\section{THEOR Y}

Procedural fairness theory is anchored in psychological social justice research. ${ }^{5}$ Social justice theory assumes that fairness is one of the fundamental norms and values in society. ${ }^{6}$ Like many powerful theories, its internal logic is simple: people experience an event and assess the fairness of their experience; these fairness assessments then generate reactions. Thus the theory is subjective in character; although rooted in objective events, fairness is an idea that exists within the minds of individuals. ${ }^{7}$

5 Lind and Tyler 1988; Tyler et al. 1997. Fair procedures are important because they: signal to people that they are respected by decision-makers (Tyler 1994; Tyler and Lind 1992), show that decision-makers can be trusted (Brockner 2002), enable individuals to reduce uncertainty about how to evaluate outcomes (Van den Bos and Lind 2002), are morally imperative (Folger, Cropanzano, and Goldman 2005; Miller 2001), lead to fair decisions, and possibly increase individuals' chances of receiving a favorable outcome (Thibaut and Walker 1975). The importance of fair procedures can also be expressed within a rational framework: people have preferences about how outcomes are generated, and when fulfilled, these preferences generate utility (Frey, Benz, and Stutzer 2004). Recently, it has been argued that a concern about procedural fairness is the result of human evolutionary history (Bøggild and Petersen 2016).

6 Folger 1984.

7 Tyler et al. 1997, 4-5. 


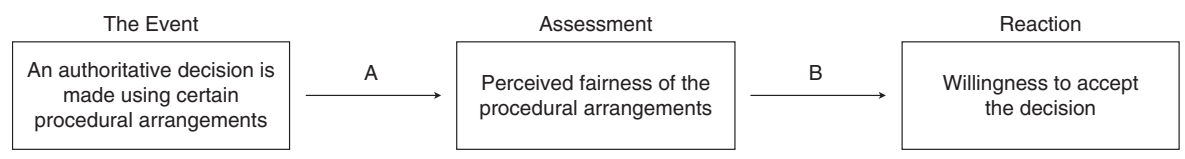

Fig. 1. Procedural fairness theory

Within this recursive three-variable framework (event-fairness assessment-reaction), procedural fairness theory stresses the procedural qualities of the experiences individuals have when subjected to authoritative decisions. The decision-making authority follows certain objective procedural arrangements (for instance, a parliamentary majority decides to raise the sales tax after an extensive debate in which different interests have presented their arguments), individuals assess the fairness of these arrangements and the assessments generate reactions (see Figure 1).

For objective procedural arrangements to translate into decision acceptance, individuals must perceive that the decision has been reached in a fair way (the causal flow denoted by $A$ ), and then consider this information important for their reactions to the decision (the causal flow denoted by $B$ ). For the objective procedural arrangement effect to be substantial, both causal flows must be strong.

A general observation about research in this field is that scholars have been focusing on the complexities of each respective causal flow (A or B) and have been less concerned with modeling the full causal chain from event to outcome reaction (A and then $\mathrm{B}$ ). ${ }^{8}$ Moreover, studies that estimate the causal impact of objective conditions on reactions to the decision frequently study outcomes other than decision acceptance, such as changes in self-esteem. ${ }^{9}$

Indicative of researchers' inclination to focus on parts of the causal chain (A or B), influential social justice scholar Van den Bos suggests that the term 'fair process effect' should be reserved for reactions that emerge out of perceived procedural fairness (causal flow $B$ ), and that effects of objective conditions on procedural fairness assessments (causal flow $A$ ) should be labeled "voice effects'. ${ }^{10}$ While this is a laudable effort to highlight the distinction between the effects of objective procedural arrangements and subjective fairness assessments, there is no term for the total impact of objective conditions on reactions (causal flow $A$ multiplied by causal flow $B$ ).

Moreover, it is common to blur the objective-subjective distinction by letting terms like 'procedures' and 'procedural factors' denote subjective assessments of procedural fairness (we do it ourselves in the introduction). A classic book in the field by Lind and Tyler spells out the logic involved: 'In order to avoid awkwardness of expression, we often write procedural justice being high or low when what we mean is that those involved feel that the process was fair or unfair. ${ }^{, 1}$ This convention might facilitate the presentation of findings, but it obscures the crucial distinction between how decisions are actually made and people's perceptions of these procedural arrangements.

${ }^{8}$ Earle and Siegrist (2008) is an exception.

${ }^{9}$ In an early phase of this project (in 2009), we surveyed 500 journal articles on procedural fairness theory. Of these, only fifty-two employed experimental manipulations of objective procedural arrangements (the remaining studies are observational and hence only study causal flow $B$ ). Of the experimental articles, only three targeted decision acceptance specifically, and no article systematically compared the strength of the respective causal flow $(A$ and $B$ ). These proportions have not changed substantially in the more recent literature (for recent studies that focus explicitly on acceptance of policy decisions, see Gash and Murakami (2015) and Towfigh et al. 2016). See the online appendix for a detailed account of the systematic literature review.

${ }^{10}$ Van den Bos 2005. The label 'voice effect' for causal flow A reflects that many social psychologists consider affected individuals' ability to express their opinion about a decision to be the single-most important procedural quality.

${ }^{11}$ Lind and Tyler 1988, 4. 


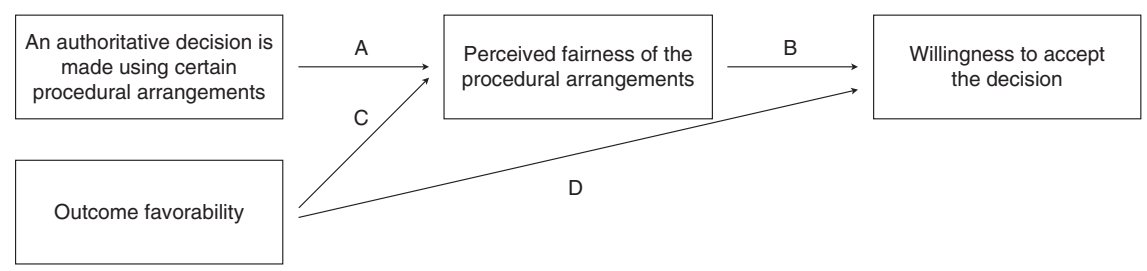

Fig. 2. How outcome favorability may intervene in the process

\section{HOW OUTCOME FAVORABILITY INTERVENES IN THE PROCESS}

In addition to maintaining the objective-subjective distinction, a properly specified model must account for how outcome favorability shapes citizens' reactions to authoritative decisions, such as the introduction of a congestion tax. It is tempting to equate outcome favorability - the degree to which a decision coincides with an individual's preference - with self-interest. However, this is not correct. Why an individual prefers one decision over another is irrelevant. The preference may be based on self-interested considerations, or on factors such as high-minded values and pro-social preferences for distributive fairness. For instance, opponents to the congestion tax may believe that it disproportionally affects poor people who have no alternative to using a car. Figure 2 illustrates how outcome favorability may intervene in the causal flows of interest here. ${ }^{12}$

First, outcome favorability may color procedural fairness assessments (causal flow $C$ ) and thereby indirectly affect decision acceptance (through causal flow $B$ ). Individuals who receive an unfavorable outcome (opponents of the congestion tax) will assess objective procedural arrangements more negatively than those who receive a favorable outcome (supporters of the congestion tax). Referring to the theory of directional motivated reasoning, ${ }^{13}$ both psychologists ${ }^{14}$ and political scientists ${ }^{15}$ have argued that procedural assessments are indeed endogenous to outcome favorability.

It is clear from a large number of experimental studies that procedural fairness assessments are anchored to a degree in objective procedural arrangements (causal flow A). ${ }^{16}$ However, as discussed above, this literature does not typically consider that even a moderately strong outcome favorability effect on procedural fairness perceptions (causal flow $C$ ) could undermine the objective fair process effect ( $A$ multiplied by $B$ ).

Secondly, outcome favorability may exert a direct effect on decision acceptance (causal flow $D$ ). When the direct effect is very strong, the subjective fair process effect (causal flow $B$ ) becomes substantially meaningless. Identifying a situation in which $D$ dwarfs $B$, Skitka and colleagues argue that procedural fairness assessments are of little importance for individuals who have a strong moral conviction on the outcome. ${ }^{17}$

12 Mullen and Skitka 2006; Skitka 2002. Another alternative discussed in the literature is that outcome favorability interacts with subjective procedural fairness assessments to mitigate negative reactions to an unfavorable outcome (e.g., Bianchi et al. 2015). Since we found no evidence of interaction effects in our data, we left out this possibility.

13 Kunda 1990; Taber and Lodge 2006.

14 Mayer et al. 2009; Skitka 2002.

15 Doherty and Wolak 2012.

16 E.g., Folger 1977; Van Prooijen, Van den Bos, and Wilke 2004.

17 For a critique of this so-called moral mandate theory, see Napier and Tyler (2008). 


\section{OBJECTIVE ARRANGEMENTS FOR POLICY DECISIONS}

Finally, an assessment of the procedure-acceptance connection must consider the objective arrangements that are available to democratic authorities. When theorizing about procedural arrangements, procedural fairness scholars have focused on three generic qualities: voice, consistency and dignity. ${ }^{18}$ Voice, which is most frequently studied, is the opportunity for individuals to present their opinions in the decision-making process. ${ }^{19}$ Consistency is the absence of systematic bias in the conduct of decision-making authorities. ${ }^{20}$ Dignity is when authorities recognize individuals' status as respected members of society during interactions. ${ }^{21}$

Voice, consistency and dignity are theoretical constructs, the effects of which are commonly studied in isolation and in abstract laboratory milieus. However, in real-world democracies these procedural qualities are embedded in complex procedural arrangements. Further complicating inquiries into real-world conditions, there are fundamental procedural differences between implementation decisions in which the government exercises authority over individual citizens (such as when an authority rejects an application for a building permit) and policy decisions that affect many people simultaneously (such as a tax hike). As observed by social psychologists Leung, Tong and Lind, most procedural fairness research targets implementation decisions. ${ }^{22}$ Because of this bias in previous research, we know comparatively little about the functioning of arrangements for policy decisions specifically.

Policy decisions are made by (a) elected representatives, (b) expert administrators in government agencies, (c) judges in the judiciary (if the constitution allows for judiciary review) and, less frequently, (d) citizens in referendums. Voice, dignity and consistency are part of all these generic policy-making arrangements, but each has additional qualities such as bringing expertise to the process.

To cover the means available to government authorities when deciding on policies, we need to make comparisons both among and within the respective types of generic procedural arrangements. Comparisons among such arrangements evaluate the extent to which it matters for decision acceptance that policies are decided by a particular generic arrangement (representative, expert, judicial and direct decision-making by the people). Correspondingly, comparisons within procedural arrangements evaluate the importance of following procedural standards for the respective type of arrangement (for example, the expectation that expert decision-makers are unbiased).

\section{DESIGN, DATA AND MEASUREMENTS}

To estimate all causal flows in the model we propose, a study must manipulate objective procedural arrangements and outcome favorability, and measure perceived procedural fairness and decision acceptance. Moreover, since our interest is in policy decisions, the study must be conducted in that context (and not in the context of implementation decisions).

In the vast procedural fairness literature, several lab experiments manipulate voice opportunities and outcome favorability in contexts that resemble implementation decisions. ${ }^{23}$ However, since policy decisions are made using different procedural arrangements than

18 For a review, see Skitka and Wisneski (2012).

19 De Cremer and Tyler 2007.

${ }^{20}$ Crosby and Franco 2003.

21 Bies and Moag 1986; Tyler and Blader 2003. Speaking of the complexity of psychological research on social justice, it is debated whether reactions to dignity processes are a separate form of 'interactional justice', which are distinguishable from procedural justice (e.g., Bies 2005).

${ }^{22}$ Leung, Tong, and Lind 2007.

23 See for example Van den Bos, Vermunt, and Wilke 1997; Van den Bos et al. 1998; Van den Bos et al. 2003. 
implementation decisions, we should be cautious when generalizing between contexts. ${ }^{24}$ Furthermore, it is important to note that many lab experiments on implementation decisions report outcome favorability effects that dwarf the objective procedural arrangement effect but regard them as manipulation checks that carry little substantial information.

The works by Skitka and Leung, Tong and Lind have sparked investigations into several of the causal processes that are central here, ${ }^{25}$ for example how procedural fairness assessments are endogenous to outcome favorability (causal flows $A$ and $C$ ), ${ }^{26}$ how issue importance may undermine the subjective fair process effect (causal flow $B)^{27}$ and how voice affects fairness assessments in a policy decision (causal flow $A$ ). ${ }^{28}$ However, while these and other studies report evidence on pieces of the puzzle, an account of the full range of relevant causal flows is missing in previous research.

Earle and Siegrist's survey experiments in Switzerland and the United States come closest to studying the full range of causal flows in our suggested model. They find that procedural arrangements are inconsequential for outcome reactions when the policy issue is important for affected individuals. ${ }^{29}$ While their study is developed within the framework of risk analysis, their findings fall well in line with our argument. However, Earle and Siegrist study general policy outcomes ('strengthening laws and treaties') rather than specific policy decisions, and the outcome of interest is citizens' willingness to support the efforts of decision-makers rather than decision acceptance specifically. Moreover, their study only considers one type of variation within one type of decision-making arrangement (in an expert decision-making process, the public is, or is not, allowed a voice). Clearly, the generalizability of the results grows with the number of decision arrangements taken into account.

\section{STUDY DESIGN}

We will report findings from twenty-seven experiments that fulfill our design requirements, and from a complementary experiment designed to test the robustness of the findings. We present the results from such a large number of experiments in order to show that our results are robust when using different settings and specifications. The main experiments are vignette (eighteen) and field (nine). ${ }^{30}$ Vignette experiments are standard in procedural fairness research, but field experiments are new to the subject area. ${ }^{31}$ Given the many data collections, we focus here on fundamental design features. The online appendix contains the detailed protocols.

In our vignette experiments, subjects were initially presented with information regarding a certain policy issue (for instance, a proposition to ban religious symbols in school). Subjects were asked to imagine that a decision on the issue was to be made that would affect them personally (for instance, to ban religious symbols in all schools in their municipality) and they were then probed about their preferred outcome (whether they personally supported a ban).

24 Leung, Tong, and Lind 2007.

25 Leung, Tong, and Lind 2007; Skitka 2002.

26 Doherty and Wolak 2012.

27 Mayer et al. 2009.

28 Terwel et al. 2010; Wu and Wang 2013.

29 Earle and Siegrist 2008.

30 Experiments were embedded in twelve original data collections, of which ten used vignettes for treatment, and two were conducted in the field.

31 With a relatively low degree of 'fieldness' (Gerber and Green 2012, 8-13), our experiments might also be labeled 'lab in the field' (Morton and Williams 2010, 296). 
Following the lead of Van den Bos, ${ }^{32}$ we thereafter primed procedural considerations by presenting subjects with a list of alternative decision-making arrangements as illustrated below:

The decision of whether to ban religious symbols in the schools in your municipality can be made in several different ways: One possibility is that the decision is made by expert administrators at the local school agency. Another possibility is that the decision is made by the politicians in the local council. A third possibility is that the decision is made by the citizens via referendum.

Following this, objective procedural arrangement and decision outcome were manipulated in the following manner:

Now that the time has come for your municipality to make the decision, the pros and cons of a ban have been debated in the media. Following the public debate, politicians in the local council // expert administrators at the local school agency // citizens in a referendum // make the final decision that religious symbols // should be banned // should not be banned // from the schools in your municipality.

To capture Outcome Favorability for each subject, the decision outcome was matched with subjects' preferred outcome as reported prior to the treatments. While this means that the proportion of 'winners' and 'losers' is dependent on the opinion sentiments among subjects, the resulting variable is evenly distributed across treatments. The proportion of 'winners' in each experiment is reported in Appendix $3 .{ }^{33}$ Perceived Procedural Fairness and Decision Acceptance were measured post-treatment.

In the field experiments, we provided a large number of high school classes with a substantial sum of money (on average, the equivalent of \$290), and asked each class to decide whether to donate it to Doctors Without Borders or to keep it for a joint celebration. ${ }^{34}$ The objective arrangements for reaching a decision were designed by us to replicate, on a small scale, decision making in large-scale democracies, and were randomly distributed across classes (for instance, the decision was made through a direct vote which was, or was not, fairly implemented).

The field experiment protocol followed the vignette experiments as closely as possible. Experimenters surveyed subjects for their favored outcome (to donate the money to charity, or to keep it for themselves), primed procedural considerations by reminding subjects that collective decisions can be made in different ways and then initiated a discussion of the merits of the two policy alternatives. When the intensity of the discussion began to fade (usually after about twenty minutes), subjects were surveyed again about their preferred outcome, and subsequently the decision was made using the randomly assigned procedural arrangement. Following the decision (our experimental manipulation), subjects assessed the fairness of the procedural arrangement that was used and stated their willingness to accept the decision.

Table 1 lists the key characteristics of the twenty-seven main experiments (E1-E27). To help readers keep track of individual studies, we include information about the study identifier from Table 1 throughout the remainder of the article and in the online appendix. The overall expectation is that objective procedural arrangements that include higher levels of personal

32 Van den Bos 2001.

33 We found no difference in reactions among the different types of losers and winners (for example, losers who opposed a proposition but received a 'pro' decision did not react differently from losers who favored a proposition but received a 'con' decision). Therefore, to save resources, the decision outcome was held constant in six of the later experiments (see the online appendix).

${ }^{34}$ In our country context, and different from the US educational system, high school classes are stable social units that study most subfields together during their entire education. From a theoretical point of view, our field experiments are thus set in a large number of natural collectives of individuals with a shared history and future. 


\begin{tabular}{|c|c|c|c|}
\hline Experiment & Manipulation of objective procedural arrangements & Policy issue & Subjects \\
\hline \multicolumn{4}{|c|}{ Comparisons among objective procedural arrangements } \\
\hline 1. Vignette & Direct vote vs. expert bureaucrats & Regulatory: Ban of religious symbols & Adults \\
\hline 2. Vignette & Direct vote vs. expert bureaucrats & Regulatory: Ban of religious symbols & Teachers \\
\hline 3. Vignette & Direct vote vs. expert bureaucrats & Regulatory: Ban of religious symbols & Students \\
\hline 4. Vignette & Direct vote vs. expert bureaucrats & Regulatory: Ban of religious symbols & Pol sci \\
\hline 5. Vignette & Direct vote vs. expert bureaucrats & Regulatory: Teachers' right to seize cell phones & Students \\
\hline 6. Vignette & Direct vote vs. expert bureaucrats & Redistributive: The use of money for charity or celebration & Students \\
\hline 7. Field & Direct vote vs. expert bureaucrats & Redistributive: The use of money for charity or celebration & Students \\
\hline 8. Field & Direct vote vs. expert bureaucrats & Redistributive: The use of money for charity or celebration & Students \\
\hline 9. Vignette & Direct vote vs. representation & Regulatory: Ban of religious symbols & Adults \\
\hline 10. Vignette & Direct vote vs. representation & Regulatory: Ban of religious symbols & Teachers \\
\hline 11. Vignette & Direct vote vs. representation & Regulatory: Ban of religious symbols & Students \\
\hline 12. Vignette & Direct vote vs. representation & Regulatory: Ban of religious symbols & Pol science \\
\hline 13. Vignette & Direct vote vs. representation & Regulatory: Teachers' right to seize cell phones & Students \\
\hline 14. Vignette & Direct vote vs. representation & Redistributive: The use of money for charity or celebration & Students \\
\hline 15. Field & Direct vote vs. representation & Redistributive: The use of money for charity or celebration & Students \\
\hline \multicolumn{4}{|c|}{ Comparisons within objective procedural arrangements } \\
\hline 16. Field & Expert decision making: voice vs. no voice & Redistributive: The use of money for charity or celebration & Students \\
\hline 17. Field & Direct vote: voice vs. no voice & Redistributive: The use of money for charity or celebration & Students \\
\hline 18. Field & Direct vote: neutrality vs. bias & Redistributive: The use of money for charity or celebration & Students \\
\hline 19. Vignette & Direct vote: secret vs. open voting & Regulatory: Ban of religious symbols & Students \\
\hline 20. Field & Direct vote: secret vs. open voting & Redistributive: The use of money for charity or celebration & Students \\
\hline 21. Vignette & Direct vote: calm vs. spiteful discourse & Regulatory: Ban of religious symbols & Students \\
\hline 22. Vignette & Representation: in- vs. out-group dominance & Regulatory: Ban of religious symbols & Students \\
\hline 23. Vignette & Representation: high vs. low turnout & Regulatory: Ban of religious symbols & Students \\
\hline 24. Vignette & Representation: unbounded vs. bounded mandates & Regulatory: Ban of religious symbols & Students \\
\hline 25. Field & Representation: unbounded vs. bounded mandates & Redistributive: The use of money for charity or celebration & Students \\
\hline 26. Vignette & Representation: lottery vs. election & Regulatory: Ban of religious symbol & Students \\
\hline 27. Field & Representation: lottery vs. election & Redistributive: The use of money for charity or celebration & Students \\
\hline
\end{tabular}


involvement and openness will yield higher levels of perceived procedural fairness and consequently - higher levels of decision acceptance. ${ }^{35}$

Experiments E1-E15 compare procedural arrangements among three generic arrangements: direct vote in a referendum, representative decision-making by elected representatives and administrative decision-making by expert bureaucrats. Given theoretical ${ }^{36}$ and empirical ${ }^{37}$ claims about the benefits of personal involvement in decision making, we contrast direct vote procedures with respective alternative arrangements.

The remaining twelve experiments (E16-E27) compare procedures within the respective procedural arrangement. Three studies focus on procedural qualities that are commonly studied in procedural fairness research: voice and consistency. E16 and E17 manipulate opportunities for voice in expert decision making and direct voting ${ }^{38}$ (that is, subjects were, or were not, allowed to discuss the merits of the proposal). E18 manipulates the neutrality of the third-party instigator in a direct vote arrangement (experimenters did, or did not, interfere in favor of the alternative that lost the initial vote by forcing subjects to vote a second time).

The final nine experiments (E19-E27) target variations within procedural arrangements that are specific to policy decisions. These treatments are new to procedural fairness research, and since we have no clear expectation about which type of arrangement will matter the most for citizens, we have identified a broad set of potentially important factors. While we cannot refer to a theoretical selection criterion, each targeted procedural arrangement is anchored in the literature on democratic policy making.

Three experiments (E19-E21) target variations within direct voting procedures: secret versus open voting ${ }^{39}$ and spiteful versus calm public discourse pre-decision. ${ }^{40}$ Finally, six experiments (E22-E27) target variations within representative decision-making: representatives are elected in high- or low-turnout elections, ${ }^{41}$ representatives are acting on bounded or unbounded mandates, ${ }^{42}$ the representatives that are elected by subjects (in-group representatives) constitute a majority or minority in the decision-making body, ${ }^{43}$ and representatives are elected or selected by lottery. 44

To further facilitate generalizability, experiments covered both regulatory and redistributive policy issues. ${ }^{45}$ Our primary regulatory policy issues concerned a proposition to prohibit students in school from wearing religious symbols such as a veil or a necklace with a crucifix (E1-E4, E9-E12, E19, E21-E24, E26). The proposal was modeled on a policy controversy in French politics. Additionally, two vignette experiments (E5, E13) focused on teachers' right to seize noisy cell phones from students.

Our redistributive policy issue is the proposal to donate money to charity or to keep it for a festivity. For experimental subjects, the proposal represents a choice between spending money on one's own welfare or redistributing the resources to the more needy. It was used throughout all the field studies (E7, E8, E15-E18, E20, E25, E27) and in two vignette experiments (E6, E14).

${ }^{35}$ Esaiasson, Gilljam and Persson 2012.

36 Pateman 1970, 26-7.

37 Dalton and Welzel 2014; Gibson, Caldeira, and Kenyatta Spence 2005; Lupia and Matsusaka 2004; Smith and Tolbert 2004; Mikael Gilljam 2009.

${ }^{38}$ Mikael Persson 2013.

${ }^{39}$ E.g., Brennan and Pettit 1990.

${ }^{40}$ E.g., Shea and Fiorina 2013.

${ }^{41}$ E.g., Lijphart 2000.

${ }^{42}$ E.g., Eulau et al. 1959.

${ }^{43}$ E.g., Phillips 1995.

${ }^{44}$ E.g., Manin 1997.

45 E.g., Lowi 1972. 
Lastly, to ensure that the results can be generalized to political controversies in large-scale democracy, our complementary experiment comprises a policy issue that at the time of the study was high on the national political agenda (to allow a local ban on begging). In the experiment, the decision was taken either by elected representatives or citizens in a referendum. The results of this robustness test will be reported separately following the main analysis.

\section{CONTEXT AND SUBJECTS}

The country context for our studies is Sweden. Since procedural effects have been reported more or less universally across economically developed countries, country context is not as important as the design and we had the ability to collect relevant data in Sweden.

For reasons of accessibility, subjects were predominantly high school students. Some would question the use of young citizens (ages sixteen to nineteen) for this purpose. While understandable, we believe the use of student subjects can be justified. Developmental psychologists have shown that high school students in contexts as diverse as Canada and China hold attitudes toward government that are similar to both each other and to the attitudes of adults. $^{46}$ In support of this argument, the experiments with young subjects reproduce the expected findings from previous research.

Moreover, we did study adult subjects in vignette experiments in a large-scale democracy setting (E1, E9) and in a school setting (E2, E10), as well as political science undergraduates in a large-scale democracy setting (E4, E12). As reported below, the results for both adults and political science undergraduates confirm what we found among high school students. Finally, we run a complementary experiment (E28) on a random sample of adult Swedes. Easing remaining doubts, this robustness test confirms the findings of our main experiments.

Adult subjects in the main experiments (E1 and E9) were recruited among travelers by bus and train at Gothenburg Central Station. The resulting diverse sample is somewhat skewed toward the elderly, but bears a reasonable resemblance to the general population (51 per cent females, $\mathrm{N}=451$ ). Adults in the school setting were recruited in connection to a one-day internal seminar for teachers and other school personnel in the Gothenburg metropolitan area (50 per cent females, $\mathrm{N}=259$ ). Political science students were recruited in connection to lectures at the University of Gothenburg and Lund University (53 per cent females, $\mathrm{N}=126$ ).

Young subjects in the vignette experiments were recruited from high schools in the metropolitan areas of Gothenburg and Stockholm $(173 \leq \mathrm{N} \geq 284)$. All experimental sessions took place in the subjects' schools and were integrated into the lessons. One field experiment involved twenty-one school classes (the level at which randomization was made) and 483 subjects at one high school unit; the other involved twelve school classes and 215 subjects at three high school units (all schools were in the Gothenburg metropolitan area). Each analysis involves a minimum of six school classes and ninety-five subjects.

We used political interest, left-right self-placement and gender as randomization controls. Appendix Tables A2a and A2b provide the results of the randomization checks: they show that in 86 per cent of cases, the covariates are balanced between the treatment groups. The validity of our manipulations is discussed in the Results section.

${ }^{46}$ See Ellenbroek et al. 2014; Helwig et al. 2007. 


\section{MEASUREMENTS AND MODELING STRATEGY}

Measurements of procedural fairness and decision acceptance were identical in all experiments. Perceived procedural fairness was captured by the item, 'How fair do you think matters were when the decision was made? ${ }^{47}$ Taking into account the nuances that are lost in translation, this is similar to standard indicators in procedural fairness research. ${ }^{48}$ Decision acceptance was measured with the item, 'How willing are you to accept and comply with the decision?' On both items, responses were registered on seven-point scales with designated endpoints.

The use of generally phrased measurements allows us to compare across decision-making arrangements and policy issues. For a validity test we have employed additional measures in several of the experiments. Whether the measures of perceived procedural fairness are generally phrased ('How fairly do you think you were treated when the decision was taken?') or adapted to specific procedural arrangements ('To what extent do you feel that you personally could affect the decision?'), all items are highly internally correlated (the inter-item simple correlation coefficient typically varies between 0.70 and 0.84 ). This suggests that the results are insensitive to the choice of precise indicator. ${ }^{49}$ As a final precaution, we included additional measurements in the complementary experiment that will be reported below.

To facilitate interpretation and comparisons of effects, all independent variables are recoded to vary between 0 and 1 . We use structural equation modeling (SEM) for estimates of direct and indirect effects to allow us to simultaneously estimate the different regression paths via mediators. ${ }^{50}$ The significance tests of the indirect effects are performed with the bias-corrected percentile interval bootstrap tests (using 1,000 bootstrap sample draws). This is a more robust estimation method than other tests of indirect effects such as the traditional Sobel test. ${ }^{51}$

In the first step we regress perceived procedural fairness on objective procedural arrangements and outcome favorability, and in the second step decision acceptance is regressed on perceived procedural fairness, decision-making arrangements and outcome favorability. This SEM model specification allows us to estimate the direct, indirect and total effects of the main independent variables in our framework on decision acceptance.

\section{RESULTS}

We begin by testing support for the notion that outcome favorability is of primary importance for decision acceptance. Our experimental design allows for a straightforward test of the proposition: we need only to estimate the total (main) effect of the objective procedural arrangement and outcome favorability on decision acceptance. To facilitate subsequent analysis, we employ SEM modeling, and express estimates in the form of unstandardized SEM regression coefficients.

The results presented in Figures 3 and 4 provide strong support for our proposition. The total outcome favorability effect is consistently about twice as strong as the total effect that follows from the objective procedural arrangement. This is the case for both comparisons between procedural arrangements (Figure 3) and within procedural arrangements (Figure 4).

47 'Hur rättvist tycker du att det gick till när beslutet fattades?' in the original.

48 E.g., Skitka, Winquist, and Hutchinson 2003.

49 Moreover, in the field experiments we included a measure of decision acceptance which more directly targeted behavioral reactions: 'When it comes to comply with, or work against, the decision, where would you place yourself?' (response scales 1-7). Overall, results are consistent with those presented in the main analyses (see Appendix Table A1).

50 Cf. Muthen and Muthen 1998-2010.

51 Shrout and Bolger 2002. 


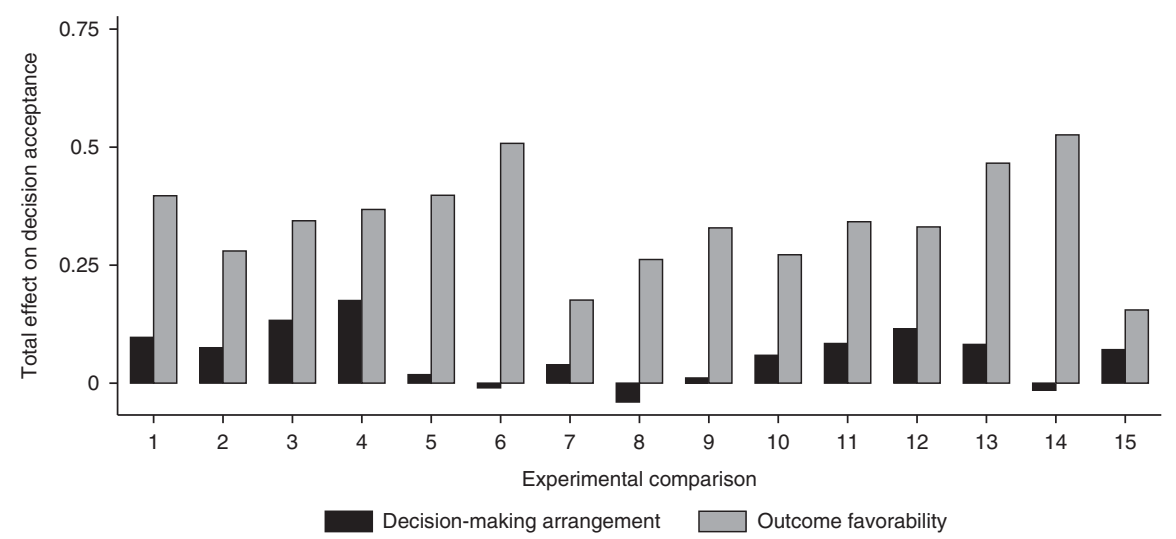

Fig. 3. Total effects on decision acceptance, among actual decision-making arrangements

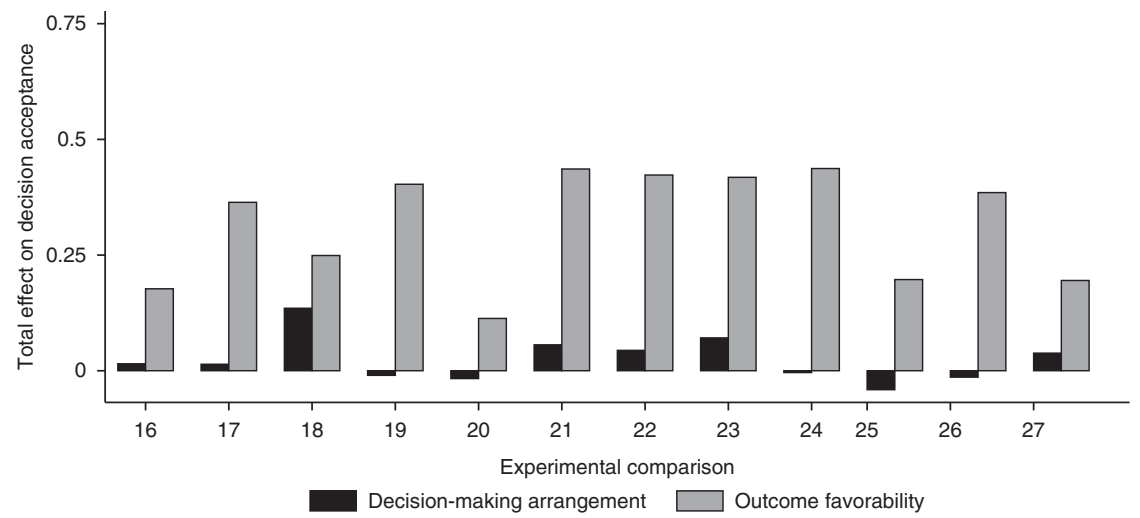

Fig. 4. Total effects on decision acceptance, within actual decision-making arrangements

Note that the results in Figure 3 represent the effects of letting the people decide by a direct vote rather than having experts or elected representatives make the decision. This is probably the single-most effective procedural arrangement available to democratic authorities in search of citizen acceptance of policy decisions, and in most polities it can only be used on rare occasions. If we instead focus on the more realistic procedural alternatives and compare expert decision making and representative decision-making, the results are even less impressive. In fact, whether the decisions were made by experts or elected representatives rarely made a difference in our subjects' decision acceptance.

Having documented support for our main claim, we turn attention to the causal processes that generate the observed outcome. To reiterate, we expect to find that procedural fairness assessments are anchored to a degree in objective procedural conditions (causal flow $A$ ), and that these fairness assessments are linked to decision acceptance (causal flow $B$ ), but also that outcome favorability directly influences procedural fairness assessments (causal flow $C$ ) and decision acceptance (causal flow $D$ ).

We estimate SEM models for the mediated and unmediated effects of theoretical interest for each experimental comparison. To confirm that the variable Perceived Procedural Fairness mediates all causality that originates from objective procedural arrangements (an assumption in 
E1

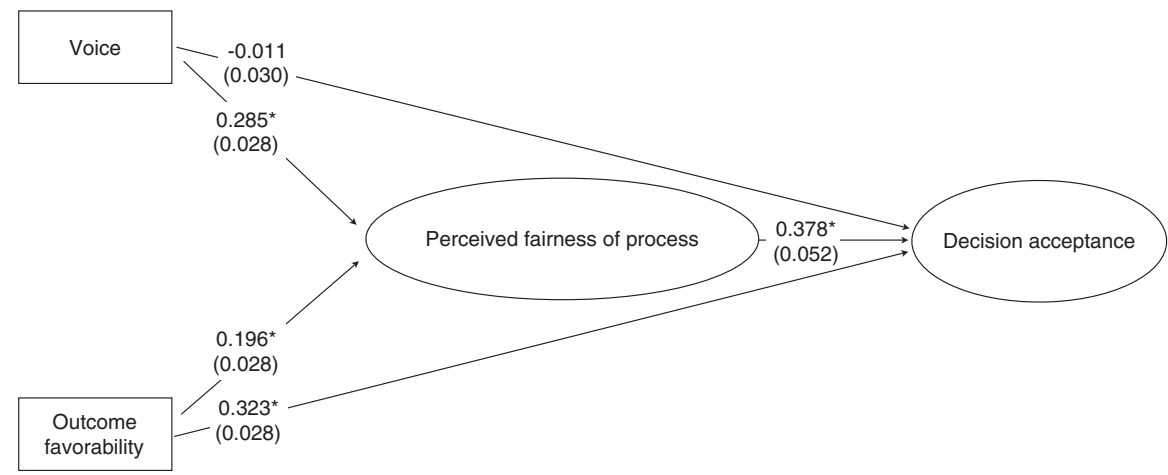

Total effect: Voice $\rightarrow$ Decision acceptance: $0.097^{\star}$

Indirect effect: Voice $\rightarrow$ Fairness of process $\rightarrow$ Decision acceptance: $0.108^{*}$

Total effect: Outcome favorability $\rightarrow$ Decision acceptance: $0.397^{*}$

Indirect effect: Outcome favorability $\rightarrow$ Fairness of process $\rightarrow$ Decision acceptance: $0.074^{*}$

$\mathrm{n}=312$

Bayesian (BIC): 912.7

Fig. 5. Effects on decision acceptance, SEM estimates

Note: $* \mathrm{p}<0.05$.

procedural fairness theory), we also allow for a (non-theorized) direct effect of the procedural arrangement on decision acceptance (that we label $E$ ). To save space, and since the results are largely consistent across studies, we only show one experimental comparison graphically, E1, which involves adults who react to a decision to ban religious symbols in schools that is made by local citizens in a referendum or by expert administrators on the local school board (Figure 5). The results from all twenty-seven studies are presented in Table 2.

With few exceptions, our data reproduce the two typical findings from previous research. In E1 and all other experimental comparisons, perceived procedural fairness has a statistically significant effect on decision acceptance (causal flow B). Correspondingly, the objective procedural arrangement has a significant effect on perceived procedural fairness in E1 and eighteen other studies (causal flow A). Moreover, corroborating that the variable Perceived Procedural Fairness captures the expected causal flows, only two studies (E18, E27) show a statistically significant and positive unmediated (non-theorized) effect of the objective procedural arrangement on decision acceptance (causal flow $E$ ).

As a validity check of our manipulations, we take a closer look at the studies in which procedural fairness assessments are decoupled from objective procedural arrangements (causal flow $A$ is not significant). Most of these studies (six of eight) target within-arrangement comparisons. At first glance, it seems problematic that a voice manipulation in E17 failed to generate a statistically significant effect on perceived procedural fairness. However, the lack of effect is less remarkable considering that voice was manipulated in the context of a direct vote procedure (subjects were or were not allowed to discuss before a use-of-money decision was made in a direct vote). Thus while voice manipulations typically generate effects, the results from E17 suggest that adding voice to an arrangement in which subjects have other opportunities to engage in decision-making does not contribute to procedural fairness assessments.

The remaining five studies manipulate objective procedural arrangements that are specific to policy decisions, and as such have not been previously noticed by procedural fairness 
TABLE 2 Effects on Decision Acceptance

\begin{tabular}{|c|c|c|c|c|c|c|c|c|c|}
\hline & E1 & E2 & E3 & E4 & E5 & E6 & E7 & E8 & E9 \\
\hline \multicolumn{10}{|l|}{ Procedural effects } \\
\hline \multirow[t]{2}{*}{ Objective procedural arrangement $\rightarrow$ Perceived procedural fairness $(A)$} & $0.285^{*}$ & 0.074 & $0.239 *$ & $0.269 *$ & $0.279 *$ & $0.210 *$ & $0.213 *$ & $0.273 *$ & $0.093 *$ \\
\hline & $(0.028)$ & $(0.049)$ & $(0.035)$ & $(0.057)$ & $(0.043)$ & $(0.072)$ & $(0.085)$ & $(0.051)$ & (0.029) \\
\hline \multirow{2}{*}{ Perceived procedural fairness $\rightarrow$ Decision acceptance $(B)$} & $0.378^{*}$ & $0.395^{*}$ & $0.269 *$ & $0.515^{*}$ & $0.437 *$ & $0.392 *$ & $0.389^{*}$ & $0.317^{*}$ & $0.476^{*}$ \\
\hline & $(0.052)$ & $(0.066)$ & $(0.061)$ & $(0.093)$ & $(0.066)$ & $(0.106)$ & $(0.110)$ & $(0.085)$ & $(0.050)$ \\
\hline \multirow{2}{*}{$\begin{array}{l}\text { Objective procedural arrangement } \rightarrow \text { Perceived procedural fairness } \rightarrow \\
\text { Decision acceptance }(A \times B)\end{array}$} & $0.108 *$ & 0.029 & $0.064 *$ & $0.138 *$ & $0.122 *$ & $0.082 *$ & $0.083 *$ & $0.087 *$ & $0.044 *$ \\
\hline & $(0.022)$ & $(0.021)$ & $(0.018)$ & $(0.047)$ & $(0.026)$ & $(0.036)$ & $(0.024)$ & $(0.021)$ & $(0.016)$ \\
\hline \multirow[t]{2}{*}{ Objective procedural arrangement $\rightarrow$ Decision acceptance $(E)$} & -0.011 & 0.045 & 0.068 & 0.036 & $-0.104 *$ & -0.092 & -0.044 & $-0.126^{*}$ & -0.033 \\
\hline & $(0.030)$ & $(0.039)$ & $(0.038)$ & $(0.058)$ & $(0.042)$ & $(0.062)$ & $(0.038)$ & $(0.045)$ & $(0.026)$ \\
\hline \multirow{2}{*}{$\begin{array}{l}\text { Objective procedural arrangement } \rightarrow \text { Decision acceptance } \\
\quad(\text { TOTAL }=A \times B+E \text { ) }\end{array}$} & $0.097 *$ & 0.075 & $0.133 *$ & $0.175 *$ & 0.018 & -0.010 & 0.039 & -0.040 & 0.011 \\
\hline & $(0.029)$ & $(0.044)$ & $(0.036)$ & $(0.060)$ & $(0.043)$ & $(0.071)$ & $(0.028)$ & $(0.037)$ & $(0.029)$ \\
\hline \multicolumn{10}{|l|}{ Outcome favorability effects } \\
\hline \multirow[t]{2}{*}{ Outcome favorability $\rightarrow$ Perceived procedural fairness $(C)$} & $0.196 *$ & $0.258 *$ & $0.323 *$ & $0.150 *$ & $0.301 *$ & $0.348 *$ & $0.170 *$ & $0.245^{*}$ & $0.172 *$ \\
\hline & $(0.028)$ & $(0.049)$ & $(0.035)$ & $(0.055)$ & $(0.043)$ & $(0.082)$ & $(0.042)$ & $(0.076)$ & $(0.029)$ \\
\hline Outcome favorability $\rightarrow$ & $0.323 *$ & $0.178 *$ & $0.258 *$ & $0.290 *$ & $0.267 *$ & $0.371 *$ & $0.110 *$ & $0.185^{*}$ & $0.247 *$ \\
\hline Decision acceptance $(D)$ & $(0.028)$ & $(0.042)$ & $(0.040)$ & $(0.052)$ & $(0.043)$ & $(0.075)$ & $(0.039)$ & $(0.054)$ & $(0.027)$ \\
\hline \multirow{2}{*}{$\begin{array}{l}\text { Outcome favorability } \rightarrow \text { Perceived procedural fairness } \rightarrow \text { Decision } \\
\text { acceptance }(C \times B)\end{array}$} & $0.074 *$ & $0.102 *$ & $0.087 *$ & $0.077 *$ & $0.131 *$ & $0.136^{*}$ & $0.066^{*}$ & $0.078 *$ & $0.082 *$ \\
\hline & $(0.016)$ & $(0.032)$ & $(0.024)$ & $(0.032)$ & $(0.031)$ & $(0.055)$ & $(0.026)$ & $(0.025)$ & $(0.018)$ \\
\hline \multirow[t]{2}{*}{ Outcome favorability $\rightarrow$ Decision acceptance (TOTAL $=C \times B+D$ ) } & $0.397 *$ & $0.280 *$ & $0.344 *$ & $0.368^{*}$ & $0.398^{*}$ & $0.508 *$ & $0.176^{*}$ & $0.262 *$ & $0.329 *$ \\
\hline & $(0.028)$ & $(0.047)$ & $(0.037)$ & $(0.059)$ & $(0.044)$ & $(0.088)$ & $(0.035)$ & $(0.046)$ & $(0.029)$ \\
\hline Number of individuals & 312 & 142 & 297 & 97 & 180 & 57 & 202 & 214 & 299 \\
\hline $\mathrm{BIC}$ & 912.7 & 437.9 & $1,001.4$ & 343.1 & 642.8 & 187.1 & 346.3 & 730.1 & 879.4 \\
\hline
\end{tabular}


Procedural effects

Objective procedural arrangement $\rightarrow$ Perceived procedural fairness $(A)$

\begin{tabular}{|c|c|c|c|c|c|c|c|c|}
\hline E10 & E11 & E12 & E13 & E14 & E15 & El6 & E17 & $\mathrm{E} 18$ \\
\hline & & & & & & & & \\
\hline & & & & & & & & \\
\hline 0 & & $377 *$ & 3* & & & & & $0.496^{*}$ \\
\hline & & & & & & & & \\
\hline & & & & & & & & \\
\hline & & & & & & & & \\
\hline & & & & & & & & \\
\hline & & & & & & & & \\
\hline & & & & & & & & \\
\hline$(0.04$ & (0.0 & & & & & & & \\
\hline & & & & & & & & \\
\hline & & & & & & & & \\
\hline & & & & & & & & \\
\hline & & & & & & & & $(0.082)$ \\
\hline & & & & & & & & \\
\hline & & & & & & & & \\
\hline & & & & & & & & \\
\hline & & & & & & & & \\
\hline & & & & & & & & \\
\hline 477.0 & 992.9 & 307.1 & 628.6 & 174.7 & 449.8 & 366.6 & 318.4 & 408.3 \\
\hline
\end{tabular}

Perceived procedural fairness $\rightarrow$ Decision acceptance $(B)$

Objective procedural arrangement $\rightarrow$ Perceived procedural fairness $\rightarrow$ Decision acceptance $(A \times B)$

Objective procedural arrangement $\rightarrow$ Decision acceptance $(E)$

Objective procedural arrangement $\rightarrow$ Decision acceptance

(TOTAL $=A \times B+E$ )

Outcome favorability effects

Outcome favorability $\rightarrow$ Perceived procedural fairness $(C)$

Outcome favorability $\rightarrow$ Decision acceptance $(D)$

Outcome favorability $\rightarrow$ Perceived procedural fairness $\rightarrow$ Decision acceptance $(C \times B)$

Outcome favorability $\rightarrow$ Decision acceptance $($ TOTAL $=C \times B+D)$

Number of individuals

$\mathrm{BIC}$

477.0 
TABLE 2 (Continued)

\begin{tabular}{|c|c|c|c|c|c|c|c|c|c|}
\hline & E19 & E20 & E21 & E22 & E23 & E24 & E25 & E26 & E27 \\
\hline \multicolumn{10}{|l|}{ Procedural effects } \\
\hline Objective procedural arrangement $\rightarrow$ Perceived procedural fairness $(A)$ & $\begin{array}{c}0.107 * \\
(0.036)\end{array}$ & $\begin{array}{c}-0.015 \\
(0.015)\end{array}$ & $\begin{array}{c}0.030 \\
(0.054)\end{array}$ & $\begin{array}{c}0.066 \\
(0.037)\end{array}$ & $\begin{array}{c}0.130^{*} \\
(0.040)\end{array}$ & $\begin{array}{c}0.072^{*} \\
(0.033)\end{array}$ & $\begin{array}{c}-0.105 \\
(0.076)\end{array}$ & $\begin{array}{c}-0.130^{*} \\
(0.034)\end{array}$ & $\begin{array}{c}-0.064 \\
(0.085)\end{array}$ \\
\hline Perceived procedural fairness $\rightarrow$ Decision acceptance $(B)$ & $\begin{array}{l}0.470^{*} \\
(0.056)\end{array}$ & $\begin{array}{c}0.605^{*} \\
(0.154)\end{array}$ & $\begin{array}{l}0.486^{*} \\
(0.077)\end{array}$ & $\begin{array}{l}0.373^{*} \\
(0.057)\end{array}$ & $\begin{array}{r}0.366^{*} \\
(0.077)\end{array}$ & $\begin{array}{l}0.407^{*} \\
(0.065)\end{array}$ & $\begin{array}{c}0.471^{*} \\
(0.072)\end{array}$ & $\begin{array}{r}0.361^{*} \\
(0.063)\end{array}$ & $\begin{array}{c}0.375^{*} \\
(0.069)\end{array}$ \\
\hline $\begin{array}{l}\text { Objective procedural arrangement } \rightarrow \text { Perceived procedural fairness } \rightarrow \\
\text { Decision acceptance }(A \times B)\end{array}$ & & $\begin{array}{c}-0.009 \\
(0.018)\end{array}$ & $\begin{array}{c}0.015 \\
(0.027)\end{array}$ & & & & & $\begin{array}{c}-0.047 * \\
(0.015)\end{array}$ & $\begin{array}{c}-0.024 \\
(0.017)\end{array}$ \\
\hline Objective procedural arrangement $\rightarrow$ Decision acceptance $(E)$ & & $\begin{array}{l}-0.0 \\
(0.0\end{array}$ & $\begin{array}{r}0.04 \\
(0.05\end{array}$ & $\begin{array}{r}0.02 \\
(0.03\end{array}$ & $\begin{array}{r}0.0 \\
(0.0\end{array}$ & & & $\begin{array}{r}0.03 \\
(0.03\end{array}$ & $\begin{array}{c}0.062 * \\
(0.019)\end{array}$ \\
\hline $\begin{array}{l}\text { Objective procedural arrangement } \rightarrow \text { Decision acceptance } \\
\text { (TOTAL }=A \times B+E \text { ) } \\
\text { Outcome favorability effects }\end{array}$ & & $\begin{array}{c}-0.017 \\
(0.025)\end{array}$ & $\begin{array}{c}0.056 \\
(0.054)\end{array}$ & $\begin{array}{c}0.044 \\
(0.036)\end{array}$ & $\begin{array}{c}0.071 \\
(0.045)\end{array}$ & & $\begin{array}{c}-0.041 \\
(0.045)\end{array}$ & & $\begin{array}{c}0.038 \\
(0.030)\end{array}$ \\
\hline favorability $\rightarrow$ Perceived proced & $\begin{array}{c}0.318^{*} \\
(0.045)\end{array}$ & $\begin{array}{c}0.135^{*} \\
(0.020)\end{array}$ & $\begin{array}{c}0.336^{*} \\
(0.068)\end{array}$ & & & & & & \\
\hline Outcome favorability $\rightarrow$ Decision acceptance $(D)$ & $\begin{array}{c}0.253^{*} \\
(0.047)\end{array}$ & $\begin{array}{c}0.031 \\
(0.023)\end{array}$ & $\begin{array}{c}0.273^{*} \\
(0.069)\end{array}$ & $\begin{array}{c}0.302^{*} \\
(0.037)\end{array}$ & $\begin{array}{c}0.359^{*} \\
(0.051)\end{array}$ & $\begin{array}{c}0.319^{*} \\
(0.048)\end{array}$ & $\begin{array}{c}0.126^{*} \\
(0.047)\end{array}$ & $\begin{array}{c}0.321^{*} \\
(0.041)\end{array}$ & $\begin{array}{c}0.147 * \\
(0.034)\end{array}$ \\
\hline $\begin{array}{l}\text { Outcome favorability } \rightarrow \text { Perceived procedural fairness } \rightarrow \text { Decision } \\
\text { acceptance }(C \times B)\end{array}$ & $\begin{array}{c}0.149^{*} \\
(0.028)\end{array}$ & $\begin{array}{l}0.082^{*} \\
(0.029)\end{array}$ & $\begin{array}{c}0.163^{*} \\
(0.042)\end{array}$ & $\begin{array}{l}0.121^{*} \\
(0.025)\end{array}$ & $\begin{array}{c}0.059^{*} \\
(0.022)\end{array}$ & $\begin{array}{c}0.118^{*} \\
(0.028)\end{array}$ & $\begin{array}{c}0.071^{*} \\
(0.030)\end{array}$ & $\begin{array}{c}0.064^{*} \\
(0.018)\end{array}$ & $\begin{array}{c}0.047^{*} \\
(0.021)\end{array}$ \\
\hline Outcome favorability $\rightarrow$ Decision acceptance (TOTAL $=C \times B+D$ ) & $\begin{array}{c}0.403 * \\
(0.037)\end{array}$ & $\begin{array}{l}0.113^{*} \\
(0.032)\end{array}$ & $\begin{array}{c}0.436^{*} \\
(0.053)\end{array}$ & $\begin{array}{c}0.423^{*} \\
(0.034)\end{array}$ & $\begin{array}{c}0.418^{*} \\
(0.040)\end{array}$ & $\begin{array}{c}0.437^{*} \\
(0.034)\end{array}$ & $\begin{array}{c}0.197 * \\
(0.052)\end{array}$ & $\begin{array}{c}0.385^{*} \\
(0.034)\end{array}$ & $\begin{array}{c}0.195^{*} \\
(0.036)\end{array}$ \\
\hline & & & & & & & & & 183 \\
\hline BIC & $1,065.3$ & 46.5 & 560.6 & 781.6 & 673.1 & 940.4 & 313.3 & 954.4 & 530.6 \\
\hline
\end{tabular}

)

Note: unstandardized SEM coefficients. Standard errors in parentheses are observed information matrix standard errors for the direct effects in the vignette experiments, clustered robust standard errors at the class level for the direct effects in the field experiments, and bootstrapped standard errors (1,000 draws) for the indirect and total effects in both vignette and field experiments. Significance levels are corroborated with bias-corrected percentile interval bootstrap tests. * $\mathrm{p}<0.05$. 
scholars: secret versus open voting (E20), calm versus spiteful discourse (E21), in-group dominance versus out-group dominance in the representative assembly (E22), unbounded versus bounded mandates (E25) and lottery-based versus election-based representation (E27). The fact that these manipulations fail to generate higher procedural fairness assessments (while outcome favorability does) is interesting for our understanding of policy decision-making processes and does not undermine the reliability of the data. Importantly, as we have seventeen experimental comparisons that reproduce all typical findings from previous research, our overall conclusion is not driven by the deviant cases.

Turning to the predictions that distinguish our study from conventional research in the field, we begin with causal flow $C$, which connects procedural assessments with outcomes. Confirming expectations, outcome favorability has a positive and statistically significant effect on perceived procedural fairness in twenty-five of twenty-seven studies. This is strong evidence that procedural fairness assessments are endogenous to the outcomes people are exposed to, especially since effect sizes are frequently on a par with, or stronger than, the effect of the objective procedural arrangement.

Support is even stronger for the second prediction, that outcomes directly affect the willingness to accept decisions (casual flow $D$ ). We register a positive and statistically significant effect of outcome favorability on decision acceptance in twenty-six of twenty-seven studies. In sum, we can conclude that when situated in a properly specified model, objective procedural arrangements are much less important than a favorable outcome for an individual's willingness to accept policy decisions.

Returning finally to the subjective procedural fairness effect (causal flow $B$ ), it is clear from our experiments that procedural fairness assessments are strongly connected to decision acceptance. Moreover, as evidenced here and in previous research, this is also true in comparison with the direct effect of outcome favorability. However, to understand the role of procedures for decision acceptance we must account for the fact that they are endogenous to outcome favorability. In other words, procedural assessments are not only affected by objective arrangements; they are also heavily affected by outcome favorability. So while procedural considerations figure prominently in people's minds when they react to policy decisions, it is unwarranted to conclude that they would have reacted much differently if the same decisions had been made using other another procedural arrangement.

\section{A ROBUSTNESS TEST}

To strengthen beliefs in our findings, we conducted a robustness test that addresses three concerns: (a) that we rely on non-probability samples consisting mostly of young citizens, (b) that we study policy issues that have a limited bearing on policy controversies in the real world and (c) that we rely on indicators of procedural fairness and decision acceptance that are imprecise measures of the underlying theoretical concepts.

To address these concerns, we designed a complementary vignette experiment (E28). To address (a), the experiment was run on a probability sample of the adult Swedish population. The fieldwork was conducted by the well-reputed survey company Novus, using their webbased 'Sweden panel'. The panel consists of randomly selected Swedes aged eighteen to seventy-nine who are recruited into the panel by telephone (mainly). The participation rate in our study was 56 per cent, which yielded 1,001 responses. $^{52}$

${ }^{52}$ For more information about the sample, see http://novus.se/vara-tjanster/sverigepanel/. 
TABLE 3 Robustness Check: Testing the Relationship in a Population-based Survey Experiment (E28)

\begin{tabular}{lcc}
\hline \hline & 1 & 2 \\
& $\begin{array}{c}\text { Identical } \\
\text { indicators }\end{array}$ & $\begin{array}{c}\text { Alternative } \\
\text { indicators }\end{array}$ \\
\hline Procedural effects & & \\
Objective procedural arrangement $\rightarrow$ Perceived procedural & $0.123^{*}$ & $0.088^{*}$ \\
fairness $(A)$ & $(0.019)$ & $(0.018)$ \\
Perceived procedural fairness $\rightarrow$ Decision acceptance $(B)$ & $0.467^{*}$ & $0.384^{*}$ \\
& $(0.026)$ & $(0.027)$ \\
Objective procedural arrangement $\rightarrow$ Perceived procedural & $0.057^{*}$ & $0.034^{*}$ \\
fairness $\rightarrow$ Decision acceptance $(A \times B)$ & $(0.010)$ & $(0.008)$ \\
Objective procedural arrangement $\rightarrow$ Decision acceptance $(E)$ & $-0.034^{*}$ & -0.030 \\
& $(0.016)$ & $(0.016)$ \\
Objective procedural arrangement $\rightarrow$ Decision acceptance & 0.024 & 0.004 \\
(TOTAL $A \times B+E)$ & $(0.018)$ & $(0.018)$ \\
Outcome favorability effects & & \\
Outcome favorability $\rightarrow$ Perceived procedural fairness $(C)$ & $0.258^{*}$ & $0.213^{*}$ \\
Outcome favorability $\rightarrow$ Decision acceptance $(D)$ & $(0.019)$ & $(0.018)$ \\
& $0.295^{*}$ & $0.295^{*}$ \\
Outcome favorability $\rightarrow$ Perceived procedural fairness $\rightarrow$ & $(0.017)$ & $(0.017)$ \\
Decision acceptance $(C \times B)$ & $0.121^{*}$ & $0.082^{*}$ \\
Outcome favorability $\rightarrow$ Decision acceptance & $(0.012)$ & $(0.010)$ \\
$\quad$ TOTAL $=C \times B+D)$ & $0.416^{*}$ & $0.377^{*}$ \\
Number of individuals & $(0.018)$ & $(0.018)$ \\
BIC & 1,001 & 1,001 \\
& $3,360.5$ & $3,385.9$ \\
\hline \hline
\end{tabular}

Note: unstandardized SEM coefficients. Standard errors in parentheses are observed information matrix standard errors for the direct effects in the bootstrapped standard errors (1,000 draws) for the indirect and total effects. Significance levels are corroborated with bias-corrected percentile interval bootstrap tests. $* \mathrm{p}<0.05$.

To address (b), the experiment targeted a policy controversy that was high on the national political agenda at the time of the study - whether to allow a local ban on begging. The issue has arisen as a result of a large influx of poor migrants of primarily Romani origin. Using the protocol from the main experiments, subjects were presented the following scenario: 'In the debate it is sometimes discussed that municipalities should be able to ban begging within its borders. What do you think about banning begging in the municipality where you live?'

To address (c), we included additional indicators of perceived procedural fairness and decision acceptance: 'How just do you think that the decision process was?' and 'When it comes to follow or oppose the decision to ban begging // not to ban begging, where would you place yourself?' As in the main experiments, responses were registered on seven-point scales with designated endpoints.

To make a good case for objective procedural arrangements, the experiment contrasted direct decision-making by referendum with representative decision-making. Using the protocol from the main experiments, respondents were randomly assigned to one of four treatments informing them (i) that the decision was taken by citizens in a local referendum // by the political representatives in the local municipality council and (ii) that the outcome of the decision was to ban begging in their 
municipality // not to ban begging in their municipality. Randomization checks confirmed that treatment groups were balanced with regard to education, age, gender and civil status.

We use an identical model specification to that in the main analyses and present the results in the left-most column in Table 3. The findings from the main experiments are replicated: perceived procedural fairness has a statistically significant effect on decision acceptance, and both the objective procedural arrangement (to decide by referendum rather than by representative decision-making) and outcome favorability have a significant effect on perceived procedural fairness. The total effect of objective procedural arrangement on decision acceptance is substantially small and not statistically significant. In contrast, the total effect of outcome favorability is significant and large in magnitude.

In the right-most column in Table 3 we present corresponding results employing the alternative indicators. Overall, the results are replicated: the total effect of outcome favorability is large and strong, while the objective procedural arrangement has an even weaker effect than in the previous model. And again we see strong effects from outcome favorability via perceived procedural fairness regarding decision acceptance.

Hence, the results from the complementary study confirm that our results are not an artifact of the specific item construction employed in the main experiments, and that the same general pattern is found in a random sample of the population and for a real-world policy controversy.

\section{CONCLUSION}

This article takes a new look at the procedure-acceptance connection in the domain of policy decisions. Our core claim is that a democratic government in search of citizen acceptance of difficult decisions is little helped by the procedural means at its disposal. In line with procedural fairness theory, our experimental data show that objective procedural arrangements affect subjective procedural fairness assessments, and that subjective fairness assessments are linked to decision acceptance. Nevertheless, when following the causal flow from objective procedural arrangements to decision acceptance, and when taking outcome favorability into account, outcome favorability is the dominant determinant of decision acceptance. These findings are consistent across regulatory and distributive policy issues, across large-scale democracy and school settings, across comparisons among and within decision-making arrangements, and across vignette and field experiments.

Based on this article, we have three recommendations for future research on the procedureacceptance connection: first, to carefully maintain the distinction between objective procedural arrangements and subjective procedural fairness assessments; secondly, to make sure that outcome favorability is fully integrated into the analysis; and thirdly, to not only study individual-level decisions, as in citizen encounters with legal authorities and street-level bureaucrats, but also policy decisions that affect large groups of citizens simultaneously. The latter recommendation is perhaps particularly important. Is it the case, as suggested by Leung, Tong and Lind, ${ }^{53}$ that procedural factors matter less when citizens react collectively to, for example, tax increases and regulation of internet use than when they are subject to decisions from planning authorities and the police?

A further topic for research is the nature of the subjective procedural fairness effect (causal flow $B$ ). To put our favored hypothesis through a tough test, we have assumed a unidirectional causal relationship from fairness assessments to decision acceptance. Since we are dealing with two closely associated attitudinal variables, this is likely an oversimplification of the true

${ }^{53}$ Leung, Tong, and Lind 2007. 
relationship. For instance, one possibility to consider is conceptual overlap: one study of people's spontaneous definitions of fair outcomes finds fuzzy boundaries between procedures and outcomes, suggesting that this may be a problem. ${ }^{54}$

Reflecting on authoritative decision-making in the real world, our results help to put procedural theory in perspective. We maintain that proponents of procedural fairness theory have been overly optimistic about democratic governments' ability to use procedural means to gain citizen acceptance of difficult policy decisions. Consider a decent democratic authority that is about to make a decision on a controversial collective matter and that wants both policy winners and losers to accept the outcome. As unfortunate as it may sound, it is unlikely that it has much to gain from trying to improve upon its current decision-making arrangements.

Regarding the scope of the argument, our focus here is on acceptance of specific policy decisions. Procedural justice researchers are increasingly emphasizing that procedural factors have long-term effects on the legitimacy of democratic authorities. ${ }^{55}$ The long-term perspective gives relevance to the finding that people's procedural fairness assessments are anchored to a degree in objective procedural arrangements. Even though people are unwilling to accept particular policy decisions because of the way they are made, fair decision-making arrangements may help to build long-term trust in authorities. Leung, Tong and Lind make a similar argument that procedural justice, collective outcomes and group identification play out differently in evaluations of authorities than in reactions to specific policy decisions. ${ }^{56}$

Finally, we want to stress a point in relation to the general relevance of objective procedural arrangements. Agreement on procedures is a civilized way to solve collective decision-making problems. ${ }^{57}$ Our study is a reminder that this insight needs to be repeated over and over again. For example, a democratic polity about to reach a decision on a controversial matter should discuss not only the pros and cons of policy options, but also the harsh reality that not all of us will get what we want on every issue. In the real world, sometimes the best we can hope for is that the decision is made according to acceptable procedural standards.

\section{ACKNOWLEDGEMENT}

Earlier versions of this article have been presented at the ECPR General Conference in Pisa, MPSA Meeting in Chicago, and a workshop on experimental research in Åbo. We are grateful to Jenny De Fine Licht, John Geer, Marcia Grimes, Andrej Kokkonen, Sofie Marien, Anders Sundell, and Chris Wlezien as well as the editors and three anonymous reviewers of the BJPS for their helpful comments and suggestions. We thank Ola Jodal, Martin Johansson, Jenny De Fine Licht, Jakob Lindahl, Erica Litzén, Anders Sundell and Rebecka Åsbrink for helping out with the data collection.

This research was supported by Grant no. 721-2004-3445 from the Swedish Research Council and Grant no. P10-0210:1 from Riksbankens Jubileumsfond (The Swedish Bank of Tercentenary Foundation).

\section{REFERENCES}

Ambrose, Maureen. 2002. Contemporary Justice Research: A New Look at Familiar Questions. Organizational Behavior and Human Decision Processes 89:803-12.

\footnotetext{
54 Lupfer et al. 2000.

55 E.g., Tyler 2006.

56 Leung, Tong, and Lind 2007.

57 Cf. Klosko 2000, 208-46.
} 
Bianchi, Emily, Joel Brockner, Kees Van den Bos, Matthias Seifert, Henry Moon, Marius van Diljke, and David De Cremer. 2015. Trust in Decision-Making Authorities Dictates the Form of the Interactive Relationship Between Outcome Fairness and Procedural Fairness. Personality and Social Psychology Bulletin 41:19-34.

Bies, Robert. 2005. Are Procedural Justice and Interactional Justice Conceptually Distinct?. In Handbook of Organizational Justice, edited by Jerald Greenberg and Jason Colquitt, 85-112. Mahwah, NJ: Lawrence Erlbaum Associates.

Bies, Robert, and Joseph Moag. 1986. Interactional Justice: Communication Criteria of Fairness. In Research on Negotiation in Organizations, edited by R. Lewicki, B. Sheppard and M. Bazerman, 43-55. Greenwich, CT: JAI Press.

Brennan, Geoffrey, and Philip Pettit. 1990. Unveiling the Vote. British Journal of Political Science 20:311-3.

Brockner, Joel. 2002. Making Sense of Procedural Fairness: How High Procedural Fairness Can Reduce or Heighten the Influence of Outcome Favorability. Academy of Management Review 27:58-76.

Colquitt, Jason, and Jerome Chertkoff. 2002. Explaining Injustice: The Interactive Effect of Explanation and Outcome on Fairness Perceptions and Task Motivation. Journal of Management 28:591-610.

Crosby, Faye, and Jamie L. Franco. 2003. Connections Between the Ivory Tower and the Multicolored World: Linking Abstract Theories of Social Justice to the Rough and Tumble of Affirmative Action. Personality and Social Psychology Review 7:362-73.

Dalton, Russell, and Christopher Welzien, eds. 2014. The Civic Culture Transformed. From Allegiant to Assertive Citizens. Cambridge: Cambridge University Press.

De Cremer, David, and Tom Tyler. 2007. The Effects of Trust and Procedural Justice on Cooperation. Journal of Applied Psychology 92:639-49.

Doherty, David, and Jennifer Wolak. 2012. When Do the Ends Justify the Means? Evaluating Procedural Fairness. Political Behavior 34:301-23.

Earle, Timothy, and Michael Siegrist. 2008. On the Relation Between Trust and Fairness in Environmental Risk Management. Risk Analysis 28:1395-413.

Ellenbroek, Moniek, Maykel Verkuyten, Jochem Thus, and Edwin Poppe. 2014. The Fairness of National Decision-Making Procedures: The Views of Adolescents in 18 European Countries. Journal of Community \& Applied Social Psychology 24:503-17.

Esaiasson, Peter, Mikael Gilljam, and Mikael Persson. 2012. Which Decision-Making Arrangements Generate the Strongest Legitimacy Beliefs? Evidence from a Randomised Field Experiment. European Journal of Political Research 51:785-808.

Eulau, Heinz, John Wahlke, William Buchanan, and Leroy Ferguson. 1959. The Role of the Representative: Some Empirical Observations on the Theory of Edmund Burke. American Political Science Review 53:742-5.

Folger, Robert. 1977. Distributive and Procedural Justice: Combined Impact of 'Voice' and Improvement on Experienced Inequity. Journal of Personality and Social Psychology 35:108-9.

- 1984. Emerging Issues in the Social Psychology of Justice. In The Sense of Injustice: Social Psychological Perspectives, edited by Roger Folger, 3-24. New York: Plenum.

Folger, Robert, Russell Cropanzano, and Barry Goldman. 2005. What is the Relationship Between Justice and Morality?. In Handbook of Organizational Justice, edited by Jerald Greenberg and Jason Colquitt, 215-45. Mahwah, NJ: Erlbaum.

Frey, Bruno, Matthias Benz, and Alois Stutzer. 2004. Introducing Procedural Utility: Not Only What, But Also How Matters. Journal of Institutional and Theoretical Economics 160:377-401.

Gangl, Amy. 2003. Procedural Justice Theory and Evaluations of the Lawmaking Process. Political Behavior 25:119-49.

Gerbner, Alan, and Donald Green. 2012. Field Experiments. Design, Analysis and Interpretation. New York: Norton.

Gibson, James, Gregory Caldeira, and Lester Kenyatta Spence. 2005. Why Do People Accept Public Policies They Oppose? Testing Legitimacy Theory with a Survey-Based Experiment. Political Research Quarterly 58:187-201. 
Gilljam, Mikael, Peter Esaiasson, and Torun Lindholm. 2009. The Voice of the Pupils: An Experimental Comparison of Decisions Made by Elected Pupil Councils, Pupils in Referenda, and Teaching Staff. Educational Assessment, Evaluation and Accountability 22:73-88.

Grimes, Marcia. 2006. Organizing Consent: The Role of Procedural Fairness in Political Trust and Compliance. European Journal of Political Research 45:285-315.

Hechter, Michael. 2013. Alien Rule. Cambridge: Cambridge University Press.

Helwig, Charles, Mary Louise Arnold, Dingliang Tan, and Dwight Boyd. 2007. Mainland Chinese and Canadian Adolescents' Judgments and Reasoning About the Fairness of Democratic and Other Forms of Government. Cognitive Development 22:96-109.

Hibbing, John, and John Alford. 2004. Accepting Authoritative Decisions: Humans as Wary Cooperators. American Journal of Political Science 48:62-76.

Klosko, George. 2000. Democratic Procedures and Liberal Consensus. Oxford: Oxford University Press. Kunda, Ziva. 1990. The Case for Motivated Reasoning. Psychological Bulletin 108:480-98.

Leung, Kwok, Kwok-Kit Tong, and Allan Lind. 2007. Realpolitik Versus Fair Process: Moderating Effects of Group Identification on Acceptance of Political Decisions. Journal of Personality and Social Psychology 92:476-89.

Levi, Margaret, and Laura Stoker. 2000. Political Trust and Trustworthiness. Annual Review of Political Science 3:475-513.

Lijphart, Arend. 2000. Turnout. In International Encyclopedia of Elections, edited by Richard Rose, 314-22. Oxford: Macmillan.

Lind, Allan, and Tom R. Tyler. 1988. The Social Psychology of Procedural Justice. London: Plenum Press.

Lodge, Milton, and Charles Taber. 2014. The Rationalizing Voter. Cambridge: Cambridge University Press.

Lowi, Theodore. 1972. Four Systems of Policy, Politics and Choice. Public Administration Review 33:298-310.

Lupfer, Michael, Kelly Weeks, Kelly Doan, and David Houston. 2000. Folk Conceptions of Fairness and Unfairness. European Journal of Social Psychology 30:405-28.

Lupia, Arthur, and John Matsusaka. 2004. Direct Democracy: New Approaches to Old Questions. Annual Review of Political Science 7:463-82.

MacCoun, Robert. 2005. Voice, Control and Belonging: The Double-Edged Sword of Procedural Fairness. Annual Review of Law and Social Science 1:171-201.

Manin, Bernhard. 1997. The Principles of Representative Government. Cambridge: Cambridge University Press.

Mayer, David, Rebecca Greenbaum, Maribeth Kuenzi, and Garriy Shteynberg. 2009. When Do Fair Procedures Not Matter? A Test of the Identity Violation Effect. Journal of Applied Psychology 94: $142-61$.

Miller, Dale. 2001. Disrespect and the Experience of Injustice. Annual Review of Psychology 52: 527-53.

Morton, Rebecca, and Kenneth Williams. 2010. Experimental Political Science and the Study of Causality: From Nature to the Lab. Cambridge: Cambridge University Press.

Mullen, Elizabeth, and Linda Skitka. 2006. Exploring the Psychological Underpinnings of the Moral Mandate Effect: Motivated Reasoning, Identification, or Affect? Journal of Personality and Social Psychology 90:629-43.

Muthen, Linda, and Muthen Bengt. 1998-2010. Mplus Users' Guide, 6th Edition, Los Angeles, CA: Muthen and Muthen.

Napier, Jamie, and Tom Tyler. 2008. Does Moral Conviction Really Override Concerns About Procedural Justice? Social Justice Research 22:509-28.

Pateman, Carole. 1970. Participation and Democratic Theory. Cambridge: Cambridge University Press.

Persson, Mikael, Peter Esaiasson and Mikael Gilljam. 2013. The Effects of Direct Voting and Deliberation on Legitimacy Beliefs: An Experimental Study of Decision-Making in Small Groups. European Political Science Review 5:381-99.

Phillips, Anne. 1995. The Politics of Presence. Oxford: Oxford University Press. 
Shea, Daniel, and Morris Fiorina. 2013. Can We Talk? The Rise of Rude, Nasty, Stubborn Politics. New York: Pearson.

Shrout, Patrick, and Niall Bolger. 2002. Mediation in Experimental and Non-Experimental Studies: New Procedures and Recommendations. Psychological Methods 7:422-5.

Skitka, Linda. 2002. Do the Means Always Justify the Ends or Do the Ends Sometimes Justify the Means? A Value Protection Model of Justice Reasoning. Personality and Social Psychology Bulletin 28:588-97.

Skitka, Linda, and David Houston. 2001. When Due Process Is of No Consequence: Moral Mandates and Presumed Defendant Guilt or Innocence. Social Justice Research 14:305-26.

Skitka, Linda, and Elizabeth Mullen. 2008. Moral Convictions Often Override Concerns About Procedural Fairness. A Reply to Napier and Tyler. Social Justice Research 22:529-46.

Skitka, Linda, Jennifer Winquist, and Susan Hutchinson. 2003. Are Outcome Fairness and Outcome Favorability Distinguishable Psychological Constructs? A Meta-Analytic Review. Social Justice Research 16:309-41.

Skitka, Linda, and Daniel Wisneski. 2012. Justice Theory and Research: A Social Functionalist Perspective. In Handbook of Psychology. Volume 5: Personality and Social Psychology, edited by Irving Weiner, Howard Tennen and Jerry Suls, 407-28. Hoboken, NJ: John Wiley and Sons.

Smith, Daniel, and Caroline Tolbert. 2004. Educated by Initiative: The Effects of Direct Democracy on Citizens and Political Organizations in the American States. Ann Arbor: University of Michigan Press.

Taber, Charles, and Milton Lodge. 2006. Motivated Skepticism in the Evaluation of Political Beliefs. American Journal of Political Science 503:755-69.

Terwel, Bart, Fieke Harinck, Naomi Ellemers, and Dancker Daamen. 2010. Voice in Political Decision Making: The Effect of Group Voice on Perceived Trustworthiness of Decision Makers and Subsequent Acceptance of Decisions. Journal of Experimental Psychology 16:173-86.

Thibaut, John, and Laurens Walker. 1975. Procedural Justice: A Psychological Analysis. Hillsdale, NJ: Erlbaum.

Tyler, Tom. 1990. Why People Obey the Law: Procedural Justice, Legitimacy and Compliance. New Haven, CT: Yale University Press.

1994. Governing and Diversity: The Effect of Fair Decision-Making Procedures on the Legitimacy of Government. Law and Society Review 28:809-31.

2000. Social Justice: Outcome and Procedure. International Journal of Psychology 35:117-25.

2006. Psychological Perspectives on Legitimacy and Legitimation. Annual Review of Psychology 57:375-400.

— 2011. Why People Cooperate. The Role of Social Motivations. Princeton. NJ: Princeton University Press: Tyler. Tom, and Steven Blader. 2003. The Group Engagement Model: Procedural Justice, Social Identity, and Cooperative Behavior. Personality and Social Psychology Review 7:349-61.

Tyler, Tom, Robert Boeckmann, Heather Smith, and Yuen Huo. 1997. Social Justice in a Diverse Society. Boulder, CO: Westview Press.

Tyler, Tom, and Allan Lind. 1992. A Relational Model of Authority in Groups. In Mark Zanna, (ed.) Advances in Experimental Social Psychology 25:115-91.

Ulbig, Stacy. 2008. Voice is Not Enough - The Importance of Influence in Political Trust and Policy Assessments. Public Opinion Quarterly 72:523-39.

Van den Bos, Kees. 2001. Fairness Heuristic Theory: Assessing the Information to Which People Are Reacting Has a Pivotal Role in Understanding Organizational Justice. In Theoretical and Cultural Perspectives on Organizational Justice, edited by Stephen Gilliland, Dirk Steiner and Daniel Skarlicki. Greenwich, CT: Information Age Publishing.

- 2005. What is Responsible for the Fair Process Effect? In Handbook of Organizational Justice, edited by Jerald Greenberg and Jason Colquitt, 273-300. Mahwah, NJ: Lawrence Erlbaum Associations.

Van den Bos, Kees, and Allan Lind. 2002. Uncertainty Management by Means of Fairness Judgments. In Advances in Experimental Social Psychology, edited by Mark P. Zanna, 1-60. Cambridge, MA: Academic Press.

Van den Bos, Kees, Marjolein Maas, Ismintha Waldring, and Gün Semin. 2003. Toward Understanding the Psychology of Reactions to Perceived Fairness: The Role of Affect Intensity. Social Justice Research 16:151-68. 
Van den Bos, Kees, Riël Vermunt, and Henk Wilke. 1997. Procedural and Distributive Justice: What Is Fair Depends More on What Comes First Than on What Comes Next. Journal of Personality and Social Psychology 72:95-104.

Van den Bos, Kees, Henk Wilke, Allan Lind, and Riël Vermunt. 1998. Evaluating Outcomes by Means of the Fair Process Effect: Evidence for Different Processes in Fairness and Satisfaction Judgments. Journal of Personality and Social Psychology 74:1493-503.

Van Houwelingen, Gijs, Marius van Dijke, and David De Cremer. 2014. Fairness Enactment as Response to Higher Level Unfairness: The Roles of Self-Construal and Spatial Distance. Journal of Management. doi: 10.1177/0149206314530166.

Van Prooijen, Jan-Willem, Kees Van den Bos, and Henk Wilke. 2004. Group Belongingness and Procedural Justice: Social Inclusion and Exclusion by Peers Affects the Psychology of Voice. Journal of Personality and Social Psychology 87:66-79.

Wu, Xuan-Na, and Er-Ping Wang. 2013. Outcome Favorability as a Boundary Condition to Voice Effect on People's Reaction to Public Policymaking. Journal of Applied Social Psychology 43:329-7. 